\title{
Specification in terms of interactional properties as a way to optimize the representation of spatial expressions
}

\author{
Viktor Pekar \\ Bashkir State University \\ Okt.Revolutsii 3a \\ 450000 Ufa, Russia \\ vpekardufanet.ru
}

\begin{abstract}
The results of the study demonstrate that numerous object-specific restrictions on the use of projective prepositions in English and Russian are predicted by their interactional (functional) semantic properties. Object-independent perceptual properties (such as distance between objects, direction of their motion, etc) that seemingly guide the use of the expressions, are also found to be presupposed by their interactional properties. Based on these findings, it is suggested that in addition to a basic geometrical specification, the semantic representation should contain functional information. A computational procedure of matching an expression with a spatial scene should thus include detection of the interactional properties of the scene. They can be determined through (1) retrieval of information about interactional properties of specific objects and (2) determining functionally relevant objectindependent perceptual properties of the scene.
\end{abstract}

\section{Introduction}

By now a number of computational models of spatial semantics have been developed, which aim to generate spatial references (e.g. Gapp,
1994; Logan and Sadler, 1996; Regier, 1996). In these models, spatial meaning is represented in terms of geometric constructs such as shapes, center of mass, distance, overlapping between shapes, etc. The models are able to appropriately match an expression with a novel spatial arrangement of shapes. However, the great disparity of real-world scenes a spatial expression can refer to presents a serious problem for this approach. There seems to be a virtually illimitable number of object- and even situation-specific restrictions on the usage of a particular expression (Herskovits, 1986). Consider, for example, the preposition in, the meaning of which is often represented in terms of the mathematical notion "inclusion". A scene where an overturned bowl is placed over a potato cannot be described by in (*the potato in the bowl), even though the potato is within the physical boundaries of the bowl. The spatial relation must be described by under: the potato is under the bowl. Hence, the lexical entry for in has to contain a comment that the preposition is not used when the Ground is a concave object positioned with its concavity opening downwards. On the other hand, a bulb, being within the boundaries of a socket, which concavity does open downwards, is said to be in the socket, but not under it. This, in its turn, has to be registered in the lexical entry as well. Taking into account the fact that the restrictions are imposed on specific orientation of specific objects, such comments in semantic representations should proliferate infinitely.

In a number of lexical semantics studies (Miller and Johnson-Laird, 1976; Herskovits, 1986; Cuyckens, 1993; Coventry, 1998; Malyar 
and Seliverstova, 1998), these restrictions are accounted by the fact that spatial meaning reflects not only perceptual experience of the referent scenes, but also their interactional (functional) conceptualization. For example, Miller and Johnson-Laird (1976) argue that the usage of the English preposition at cannot be predicted by such notions as "contiguity" or "juxtaposition". There are situations, where these types of relations hold, but the preposition cannot be used: *The chair is at the ocean liner. *Bill is at Australia. To define the meaning of $a t$, they introduce the notion "region" of an object $\mathrm{x}_{-}$a portion of space "where $\mathrm{x}$ can interact with $y$ socially, physically, or in whatever way x's conventionally interact with $y$ 's". The notion of "interaction" explains inappropriateness of at in the two sentences: a chair and an ocean liner, as well as a person and a big body of land normally do not interact with each other.

However, it remains unclear how the perceptual and functional properties relate to each other. Malyar and Seliverstova (1998) for some English and Russian prepositions propose that function is a factor complementing geometry in predicting the usage: in those uses, where the available geometrical semantic information does not correctly indicate the Figure's position, it is delineated by the notion "function" of the Ground. Cuyckens' (1993) analysis of the Dutch in similarly suggests that in most cases its meaning can be represented by geometric constructs like "three-dimensional", "porous", "bounded", etc; and in cases, where geometric specification fails to explain the usage, the notion "function" is employed (notably for the case with the overturned bowl and potato). This solution, however, seems counter-intuitive: it requires that some portion of uses is determined by geometry and some by function and thus the meaning representation still has to explicitly encode specific cases, where geometrical description is inappropriate. From the computational perspective, this representation is also hardly plausible.

\footnotetext{
${ }^{1}$ Miller and Johnson-Laird (1976) use ' $x$ ' to refer to the object denoted by the left argument of the preposition and ' $y$ ' for the object denoted by the right argument of the preposition. In the present paper to designate these entities the terms 'Figure' and 'Ground', respectively, will be used.
}

The present study attempts to verify the hypothesis that a functional property of a preposition presupposes its different perceptual properties. If the hypothesis is verified, the finding will explain why numerous perceptually diverse uses of a preposition fall under one linguistic category. The meaning of a preposition could then be specified in terms of function while omitting the many restrictions necessary in a geometry-based semantic representation.

The paper focuses on projective prepositions - the English above and over and the Russian вперед $u$ and nepe ${ }^{2}$. Projective prepositions present an interesting subject matter in the context of study of spatial reference. Coventry's (1998) analysis of a number of synonymic pairs of English projective prepositions (including above and over) demonstrated that function plays a significant role in their semantics. The present study is to check if the usage of the Russian prepositions is also influenced by function. Comparison between semantics of the vertical and frontal prepositions may reveal certain cross-domain regularities of correlation between perceptual and functional semantic properties.

\section{Methodology}

The first stage of the study was concerned with formulation of hypotheses about particular character of perceptual and functional properties of the prepositions. For this purpose examples of the authentic usage of the prepositions in electronic corpora (the Brown corpus, the Lancaster-Oslo-Bergen corpus, the British National Corpus, the Times (March 1995)) were collected. The corpus data were supplemented by usage examples found in literary English and Russian texts. This stage revealed important distributional characteristics of the prepositions. For example, it was found that over very rarely combines with verbs denoting an upward motion, such as rise, raise, lift, heave, soar, while above often does. Hypotheses about a given preposition were formulated in terms of properties of referent scenes that tend to be described by this preposition. The hypotheses

\footnotetext{
${ }^{2}$ The both prepositions denote the Figure's position on the frontal axis of the Ground.
} 
were tested in experiments with native speaking subjects.

During the experiments subjects' judgements about appropriateness of the use of the prepositions in selected contexts were obtained. The methodology is based on the assumption that an expression is judged to be semantically acceptable in a context, if this context possesses semantic features that are either the same as those of the expression or do not contradict them; the expression is unacceptable, if the context contains semantic properties, contradicting those of the expression. Thus, presence of a semantic property in the meaning of a preposition was verified in the following manner. In the context, which possessed the examined semantic property, first one and then the other of the contrasted prepositions were placed. If there was a statistically significant difference in distribution between subjects' evaluations of the two sentences, presence of the property in the semantics of a preposition was taken to be verified. The use of linguistic data in the experiments is particularly suited for the purposes of the study, because it allows for dealing with non-perceptual semantic properties, as opposed to obtaining linguistic responses to purely perceptual stimuli, e.g. pictures of geometric shapes.

23 English-speaking subjects participated in the experiments. They represented the American and British varieties of English (20 and 3 subjects, respectively). Their age ranged between 25 and 60 . All of them were college graduates. As Russian-speaking subjects, 45 graduate and undergraduate students of the English Language Department of Bashkir State University (Ufa, Russia) were recruited, their age ranging between 18 and 30 .

During the experiment the subjects were presented with questionnaires, each containing about 30 pairs of identical sentences, which differed only in the prepositions used. The sentences used were edited authentic examples of the use of the prepositions. The subjects were instructed to evaluate appropriateness of the use of the prepositions in the sentences according to a 5-degree scale. In case they perceived a sentence as ambiguous, they were asked to point it out and leave it unevaluated.

The difference between the pairs of sentences thus formed was analyzed in terms of the
Student $\mathrm{t}$ criterion and the chi-square criterion. The difference in evaluations between the sentences (and hence between the semantics of the prepositions) was taken to be established, if the $\alpha$ value was smaller than 0.05 . In the following discussion, paired sentences with $\alpha<0.05$ are used as examples, with the preposition having smaller mean of evaluations marked by an asterisk.

\section{Perceptual Properties}

The section describes the revealed perceptual semantic properties of the four prepositions, which do not depend on specific objects and namely those properties which pertain to motion of the Figure, distance between the Figure and the Ground and choice of reference frame $\mathrm{e}^{3}$. The usage of over and neped, one the one hand, and above and вnередu, on the other, was found to be sensitive to largely the same perceptual properties of referent scenes.

\subsection{Choice of Reference Frame}

The prepositions вnepedu and above were found to be used when the position of the Figure is described in the egocentric reference frame:

(1) Впереди стола стоит стул. 'There is a stool ahead of the table.'

(2) The roof of my school could be seen above (*over) those trees.

Example 1 implies that the stool and the table are located on the frontal axis of the observer, the table being closer to the observer than the stool (Figure1) (compare: Перед столом cтоит стул. 'There is a stool in front of the table.' which does not imply the presence of the observer). In 2 the position of the Figure roof relative to the Ground trees is described simultaneously in the absolute reference frame (relative to the gravity axis) and the egocentric reference frame: the roof is not directly over the trees; the roof and the trees are vertically corelated only from the point of view of the

\footnotetext{
${ }^{3}$ Strictly speaking, reference frame is not a perceptual property of a scene, but a strategy of organizing the perceptual input. For our purposes, it is important that descriptions in different reference frames invoke different percepts. For example, John is to the left of Mary in the egocentric reference frame denotes different spatial relations than the same sentence in the intrinsic reference frame.
} 
observer, whose position is implied - it is on one horizontal line with positions of the trees and the school (Figure2).

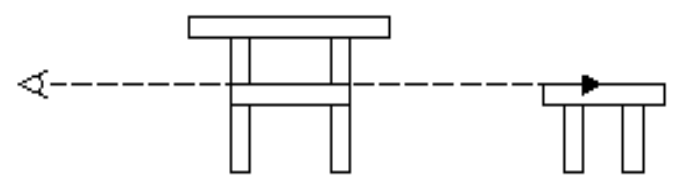

Figure 1. Egocentric reference frame in the usage of впередu in (1).

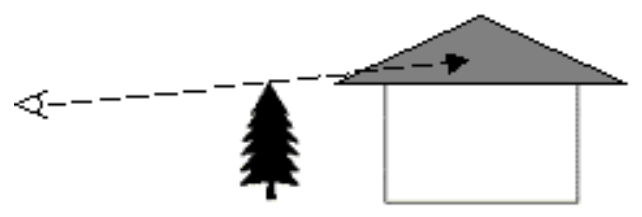

Figure 2. Egocentric reference frame in the usage of above in (2).

The prepositions neped and over are used when the position of the Figure is described in the intrinsic reference frame:

(3) Почтальон перед почтовым ящиком. 'The postman is in front of the mailbox.'

(4) He held the hammer over the nail.

In 3 the position of the postman is defined relative to the frontal axis of the mailbox; the position of the observer is not implied - he or she can in principle be viewing the scene from any point (Figure 3 ). In 4 the position of the hammer is defined relative to the gravity axis and the vertical axis of the nail, also irrespective of the observer's position (Figure 4).

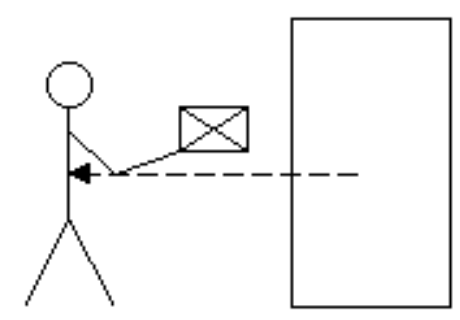

Figure 3. Intrinsic reference frame in the usage of nеред in (3).

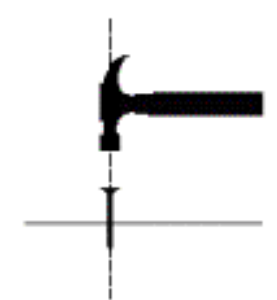

Figure 4. Intrinsic reference frame in the usage of over in (4).

\subsection{Motion of the Figure}

The preposition over is found to be used to denote Goal (i.e. the end-point of a trajectory) of a downward motion of the Figure toward the Ground (5). It can also denote Source (i.e. the starting point of a trajectory) of an upward motion of the Figure away from the Ground (6):

(5) He pulled his cap down over (*above) his eyes.

(6) The executioner removed his sword from over (*above) Peter's head.

The preposition above, on the contrary, is used to denote Goal of an upward motion of the Figure away from the Ground (7) and Source of a downward motion of the Figure toward the Ground (8):

(7) He raised his cap above (*over) his eyes.

(8) A meteorite falling from above (*over) us.

In Russian to denote Goals and Sources of the Figure's motion on a horizontal plane the prepositions $\kappa$ (Goal of motion toward the Ground), om (Source of motion away from the Ground), вперед (Goal of motion away from the Ground) and cnepedu (Source of motion toward the Ground) are used. However, the prepositions nеред and впереди have different degrees of acceptability when different Paths (i.e. trajectories) of the Figure's motion along the Ground's frontal axis are in question. The preposition neped is preferred, when motion is toward the Ground (9) and впередu when motion is away from the Ground (10):

(9) Из-за угла прямо на него вылетела машина и остановилась только перед ним (*затормозила только впереди него). 'A car raced from around the corner and stopped just in front of him.'

(10) Впереди меня лыжники стали быстро удаляться (*удаляться передо мной). 'Тhe skiers ahead of me started to quickly enlarge the gap.' 
Thus, neped, like over, emphasizes Goal of the Figure's approaching the Ground, while вnередu, like above, emphasizes Goal of the Figure's departing from the Ground.

\subsection{Distance between the Figure and the Ground}

The prepositions вnеред $u$ and above are used when distance between the Figure and the Ground is conceptualized as great.

(11) Дерево, стоящее далеко впереди нас (*далеко перед нами). 'A tree standing far ahead of us.'

(12) Keep the grill high enough above (*over) the fire!

The prepositions can be used when between the Figure and the Ground there are some other objects of a size, comparable to that of the spatially co-related objects.

(13) He lives three floors above me (*three floors over me).

(14) Он встал в очередь и заметил, что через три человека впереди него стоял Владимир (*через три человека перед ним). 'He took a place in the line and saw Vladimir standing three people ahead of him.'

Presumably the presence of such objects between the Figure and the Ground motivates conceptualization of distance / remoteness between them. Of conceptualization of distance between the Figure and the Ground in occurrences of above and впередu also speaks the fact that these prepositions, unlike their synonyms, are used when degree of remoteness of one object from the other is specified. These are those cases when the prepositions are combined with words and phrases like one inch, several feet five hundred meters, slightly, a little (15 and 16), etc.

(15) She stuck the rose in her hair a little above the left ear $(* a$ little over the left ear).

(16) Чуть впереди Алексея бежал Владимир (*чуть перед). 'Vladimir was running a little ahead of Aleksey.'

The prepositions neped and over are used when the distance between the Figure and the Ground is not conceptualized at all:

\footnotetext{
${ }^{4}$ It is of interest to note that above and вnepedu can combine with words like slightly or a little, but not with very, too, considerably, quite: *quite above, *довольно впереди.
}

(17) Перед ним лицом к лицу стоял Владимир (*Впереди него лицом к лицу). 'In front of him face to face stood Vladimir.'

(18) His cap was low over (*above) his eyes.

That the prepositions are used when distance is negligible is also seen from the fact that they are inappropriate in cases when there are some other sizeable objects between the Figure and the Ground (13-14) or when degree of remoteness is emphasized (15-16).

The prepositions over and neped are also used to denote the point where the Figure is traversing a projective axis of the Ground, typically at such a distance from it, that conceptualized as negligibly small and also not excluding a contact between the objects

(19) Ребенок перебежал дорогу прямо перед грузовиком (*... перебежал дорогу прямо впереди грузовика.) 'The child dashed across the street right in front of a truck.'

(20) The ball flew over the fence. (*The ball flew above the fence.)

Their synonyms cannot denote this point on a projective axis of the Ground: впередu is unacceptable in 19 and above in 20 conveys information of the Figure's moving along a projective axis of the Ground away from it.

\section{Functional Properties}

The study revealed that both the Russian and the English prepositions possess functional semantic properties, and namely their meaning is characterized by information about certain interaction, currently taking place or anticipated, between the spatially co-related objects. The prepositions neped and over convey information about functional interdependence between the objects, whereas the prepositions вперед $u$ and above - of functional separation or independence of the objects.

The first type of functional information is physical interaction between the Figure and the Ground, which is taking place at the moment in question. The result of this interaction is usually change of some physical (integrity, temperature, etc) or interactional (visibility, possibility to manipulate, etc) characteristic of one of the objects. One of the objects - which may be both

\footnotetext{
${ }^{5}$ Such uses of over can be considered boundary cases between the 'above' and 'across' senses of the preposition.
} 
the Figure and the Ground - is seen as a source of influence or an agent of an action directed at its counterpart. Animate objects can act in the role of the influencing object, as well as those inanimate objects that are able to disperse light, heat, etc or used as instruments:

(21) She bent over (*above) the puppies to see them better.

(22) Мы грелись, стоя перед (*впереди) плитой. 'We were keeping warm standing in front of the stove.'

(23) Footsteps thumping heavily above (*over) the boys.

(24) Впереди него ежеминутно разрывались бомбы (*Перед ним ежеминутно разрывались бомбы). 'Bombs were constantly exploding ahead of him.'

In 21 and 22 there are functional relations between the objects. In 21 the Figure she is directing the action of inspecting at the Ground puppies. Note that here not a simple act of perceptually spotting an object is implied, but an active examination of it. In 22 the Figure $\mathbf{~} \mathbf{~ b l}$ 'we' experiences influence exerted by the Ground плита 'stove'. In 23 and 24 the objects are functionally disjunct. In 23 the action of the Figure footsteps does not effect the Ground the boys, if above is used; and does so, if over is replaced for above. In 24 the process разрывались бомбы 'exploding' is understood as not effecting the Figure него 'him', cf. $O H$ был убит разорвавщейся перед ним бомбой. 'He was killed by a bomb that exploded in front of him.'

Second, the prepositions can describe such functional relations, whereby one object is conceptualized as protecting the other one from influence from without the functional unity:

(25) He carefully held his hat over (*above) the candle to protect it from the rain.

(26) The fog over (*above) the river prevented detection from airplanes.

(27) Скрывая лицо от фотокамер, он держал папку перед собой (*впереди себя). 'Trying to conceal himself from the cameras he held his file in front of his face.'

(28) Перед оратором держали пуленепробиваемое стекло (*впереди оратора). 'А bulletproof shield was held in front of the speaker.'

Third, the relations between objects can be conceptualized in such a manner that one object is seen as having a potential to establish an influence over the other one; at the moment in question, however, no influence is exerted. To describe this type of relations the term "functional potential" will be used, which was introduced by Miller and Johnson-Laird (1976) to designate a similar interactional property of artifacts.

(29) Trying to threaten Peter, the executioner held his sword over (*above) his head.

(30) A black stormy cloud over (*above) the farm.

(31) Перед ним поставили тарелку, подождав немного, он взял ложку и начал есть (*Впереди него поставили тарелку). 'A plate was placed in front of him, he waited a little, then took the spoon and started to eat.'

(32) На моем рабочем столе передо мной лежит письмо (*впереди меня). 'There is a letter on my desk, right in front of me.'

To sum up, the prepositions over and neped are found to convey information of three identical types of functional relations between the Figure and the Ground: actual physical interaction, protection, functional potential; the prepositions above and впередu convey information of absence / impossibility to establish such functional relations. As is clear, the functional properties presuppose perceptual properties that are specific for particular objects.

\section{Correlation between Functional and Perceptual Properties}

The study revealed that each of the three types of the object-independent perceptual properties of each of the prepositions can be present in one referent scene simultaneously together with the functional property of this preposition, but not with the one contradicting it. This regularity is established from subjects' acceptability judgements of sentences where information about either presence or absence of functional relations is added to information about a particular object-independent perceptual property.

The study replicated results of CarlsonRadvansky and Irwin (1993), who demonstrated correlation between presence of functional relations and choice of the intrinsic reference frame, on the one hand, and between absence of functional relations and choice of the egocentric reference frame, on the other. For example, in 3, where, as it was shown, choice of the intrinsic 
reference frame necessitates the use of neped, the postman's position is such that allows functional interaction between him and the mailbox (the postman may be taking mail out of the mailbox). If it is manifestly shown that the postman cannot interact with the mailbox, впереди (or some other preposition like около 'near') is preferred to neped:

(37) Почтальон стоял впереди / около почтового ящика, разговаривая с дворником. (*Почтальон стоял перед почтовым ящиком, разговаривая с дворником.) 'The postman was standing ahead of / near the mailbox, talking to a roadsweeper.'

In 4 , where the intrinsic reference frame is also chosen, the position of the hammer is such that allows its functional interaction with the nail. Both in 3 and 4 the Figures (the postman and the hammer) and the Grounds (the mailbox and the nail) are conceptualized as facing each other by their functionally relevant sides.

In uses of впередu and above, absence of functional relations between the Figure and the Ground can combine with choice of the egocentric reference frame. In 1 the stool and the table do not necessarily face each other by their functional sides, the two objects do not have to constitute a functional unity. For example, the stool may be at such a distance away from the table that a person seated on it cannot interact with the table. The co-position of the trees and the roof described in 2 does not allow any sort of interaction between them.

The Figure's approaching the Ground (38a) and an insignificantly small distance between the two objects (39a) are found to correlate with the emergence and the presence of functional relations between them, correspondingly.

(38a) He pulled his lamp down over his sheets to see the scheme better.

(38b) *He pulled his lamp down over his sheets so that it does not obstruct the view.

(39a) The helicopter was hovering low over the boat to save the crew.

(39b) *The helicopter was hovering low over the boat in order not to be detected.

The Figure's departing from (40a) and a big distance between the two objects (41a) correlate with discontinuation and absence of functional relations between them. (40a) To let the sun rays play on his face he pulled his cap up above his eyes.

(40b) *To conceal his face from the sunrays, he pulled his cap up above his eyes.

(41a) She sat on a branch high above the lions so that they could not get at her.

(41b) *She sat on a branch high above the lions and fed them.

Examples $38 \mathrm{~b}, 39 \mathrm{~b}, 40 \mathrm{~b}$ and $41 \mathrm{~b}$ show that the opposite is not possible. In a given scene, perceptual properties, corresponding to those of a given preposition, cannot combine with the functional properties that contradict those of this preposition. As is easily seen, this regularity is not just a peculiarity of the prepositions, but rather a matter of common sense. Removing the prepositions and expressing the idea in any other words cannot make the sentences semantically well-formed: *The helicopter was hovering low in order not to be detected from the boat. *She sat high on a tree branch and fed the lions. It can be expected that other prepositions, which possess the same functional properties, also possess corresponding perceptual properties.

From the correspondences between the object-independent perceptual properties of a preposition and its functional property, one can conclude that the two types of semantic properties presuppose each other. The perceptual properties can be said to be functionally relevant, that is, perceiving these properties, the observer forms an idea about the functional aspect of the scene. For example, one object's approaching some other one automatically triggers conceptualization of a possibility that the former influences the latter.

\section{Conclusion}

The English vertical above and over and the Russian frontal nеред and впередu are found to possess similar object-independent perceptual properties, which pertain to motion, distance, and choice of the reference frame. All the four prepositions are also found to have similar functional properties - their usage is sensitive to (1) interaction between the Figure and the Ground that is currently taking place; (2) the Figure's preventing the Ground from being physically influenced ("protection"); (3) potential interaction between the objects ("functional potential"). Conceptualization of interaction in these cases hinges on experiential 
knowledge about functionality of specific objects. For example, a human is usually conceptualized as (potentially) acting upon an object, located near him/her. The fact that specific objects are perceptually different, but have the same functional status, explains objectspecific restrictions necessary in a geometrybased semantic specification.

The object-independent perceptual properties of referent scenes that determine the usage of the prepositions are found to be functionally relevant, i.e. by perceiving these properties the observer is able to form an idea about the functional aspect of the scene. That is why functional relations are conceptualized even in those cases when the spatially correlated objects do not have any inherent function (i.e. "natural kind objects" like clouds, fog, or rocks). These are such cases when, for example, small distance triggers off conceptualization of potential interaction between objects, or great distance impossibility of interaction.

Thus, the object-specific and objectindependent perceptual properties of each of the four prepositions are presupposed by its functional property. The established correlation between the perceptual and functional properties allows not to keep geometry and function distinct in the lexical entries, and thus to avoid the necessity to explicitly specify cases that are determined by geometry and cases that are determined by function. On this account, an optimal semantic representation will include only functional semantic properties and information about the particular projective axis on which the Figure is located.

Based on these findings, a computationally plausible procedure of matching a preposition with a referent scene may be proposed. The procedure should include detection of the functional properties of the scene. They can be determined through (1) retrieval of interactional information about specific objects, e.g. their functionally relevant sides; (2) functionally relevant object-independent perceptual properties of the scene, e.g. distance between objects, direction of their motion, etc. After that the scene is described by that preposition that possesses the corresponding functional semantic property.

The conducted study, however, does not allow one to think that meanings of the vertical and the frontal prepositions are entirely identical. The frontal prepositions впередu and neped, unlike the vertical prepositions above and over, cannot denote Goal and Source of the Figure's motion: there are special prepositions to denote these entities. Nonetheless, such cases are not numerous and can be presented as exceptions in the lexical entries without making the semantic representation too bulky and unmanageable.

\section{References}

Laura A. Carlson-Radvansky and D. E. Irwin. 1993: Frames of reference in vision and language: Where is above? Cognition 46:223-244.

Kenny R. Coventry. Spatial prepositions, functional relations and lexical specification. The representation and processing of spatial expressions. Mahwah, 247-262.

Hubert Cuyckens. 1993: The Dutch spatial preposition "in": a cognitive semantic analysis. The semantics of prepositions: from mental processing to natural language processing. Berlin, 27-71.

Klaus P. Gapp. 1994. Basic meanings for spatial relations: Computation and evaluation of $3 \mathrm{D}$ space. Proceedings of AAAI-94: 1393-1398.

Annette Herskovits. 1986: Language and spatial cognition: an interdisciplinary study of the prepositions in English. Cambridge.

Gordon D. Logan and Daniel D. Sadler. 1996: A computational analysis of the apprehension of spatial relations. Language and Space. Cambridge, MA, 493-529.

Tatiana N. Malyar and Olga N. Seliverstova. 1998: Prostranstvenno-distanzionnye predlogi i narechiya $\mathrm{v}$ russkom i angliyskom yazykakh. Slavistische Beiträge 362. München.

George Miller and Phillip Johnson-Laird. 1976: Language and perception. Cambridge, MA.

Terry Regier. 1996: The human semantic potential. Spatial language and constrained connectionism. Cambridge, MA. 